\title{
A Survey on Domestication and Foreinization Theories in Translation
}

\author{
Lili Wang \\ Qingdao University of Science and Technology, Qingdao, China
}

\begin{abstract}
The two translation strategies domestication and foreinization each has a long history of development. Both domesticating and foreinizing translation are products of a given culture and society. The choice of translation strategies is not haphazard but context-bound. Thus domestication and foreinization should be viewed in a historical and dynamical way.
\end{abstract}

Index Terms - domestication, foreinization

As two major translation strategies, domestication and foreignization have long been the focus of the debate in translation circle. The former is "a term used to describe the translation strategy in which a transparent, fluent style is adopted in order to minimize the strangeness of the foreign text for target readers" and the latter "is used to designate the type of translation in which a target text is produced which deliberately breaks target conventions by retaining something of the foreignness of the original" (Shuttleworth and Cowie, 2004, p59). Opinions of different translation theorists diverge in the choice between the two translation strategies in translation practice. But reviewing the development of these two strategies, it is easy to find out that both of them are deeply rooted in specific social and cultural circumstances. In other words, the choice of domesticating and foreinizing strategies is not only made by the translators, but more importantly, made by the specific social situations.

\section{DOMESTICATION}

Domesticating strategies have been implemented at least since ancient Rome (Baker, 1998). In 300 BC, Greece was conquered by Rome and the Romans began to consider translation as "a form of conquest"(Tan, 1991, p22). As a result, "Latin translators not only deleted culturally specific markers but also added allusions to Roman culture and replaced the name of the Greek poet with their own, passing the translation off as a text originally written in Latin" (Baker,1998, p241).

In $46 \mathrm{BC}$, Cicero, a representative of ancient western translation theory, concluded from his translation practice of the speeches of the Attic orators Asechines and Demosthenes:

I did not translate them as an interpreter, but as an orator, keeping the same ideas and. forms, or as one might say, the figures of "thought", but in language which conforms to our usage. And in doing so, I did not hold it necessary to render word for word, but I preserve the general style and force of the language. (Munday, 2001, p19)

Apparently, there was a dichotomy of translation strategies into free translation and "word for word" translation. "An orator" was to produce free translation in which the ideas and thought of the original work were retained while "an interpreter" was to give "word for word" translation or namely literal translation. Cicero was in support of free translation and labeled literal translation as the work of the unskilled and insisted that the latter should be avoided.

At the end of the fourth century, Saint Jerome cited the authority of Cicero's approach to justify his own Latin translation of the Greek religious works. He described his translation strategy as "I render not word-for-word, but sense -for- sense" (Munday, 2001, p20). In his opinion, adhering to the form of the source text would produce an absurd translation and cover the sense of the original. The primary work of a translator was to convey the ideas and contents of the source text in the target language, but the words in the source text to express such ideas and contents were dispensable. To illustrate the concept of the target language taking over the sense of the source text, Jerome used the military image of the original text being marched into the target language like a prisoner by its conqueror (Robinson, 1997). After Jerome, the discussion on free and literal translation lasted for more than one thousand years: John Dryden advocated "paraphrase" that involved changing whole phrases and more or less corresponded faithful or sense-for-sense translation. His free translation method in his version of Aeneid was so complete that "fluency" was seen to be "a feature of Virgil's poetry instead of the strategy implemented by the translator" (Venuti, 2004). In his essay "On the Principle of 7ianslation" in 1791, Alexander Fraser Tytler put forward famous three "laws": "The Translation should give a complete transcript of the ideas of the original work; The style and manner of writing should be of the same character with that of the original; The translation should have all the ease of original composition (p16).

They represented two different opinions about translation: faithfulness of content and faithfulness of form, and can be viewed as the reformations of the sense-for-sense and word-for-word dichotomy by Cicero and St Jerome. After centuries of debates on literal and free translation from Cicero to the twentieth century, the 1950s began to witness the theoreticians' systematic analyses of translation. Roman Jakobson introduced the notion of "equivalence in difference" 
in his paper "On Linguistic Aspects of Translation" in 1959 which gave new push to the theoretical analysis of translation. In 1964, Eugene A. Nida formulated his concept of "dynamic" or "functional equivalence" in translation and later restated and developed them. "A translation of dynamic equivalence aims at complete naturalness of expression," said Nida, "and tries to relate the receptor to modes of behavior relevant within the context of his own culture" (Toward a Science of Translating p159). The phrase "naturalness of expression" signaled "the importance of a fluent strategy to this theory of translation and it is obvious that fluency involves domestication" (Venuti, 2004). Nida proposed that "the translator must be a person who can draw aside the curtains of linguistic and cultural differences so that people may see clearly the relevance of the original message" (Nida and Waard, 1986, p14). He transferred the focus from the comparison between the original text and the translated version to the comparison between the two communicative processes and took every linguistic and cultural factor which was possible to affect the reception of information into consideration. He said that "the new focus, however, has shifted from the form of the message to the response of the receptor"(Nida and Taber, 1969, p738). And he contended that an ideal translation should have the same effect on the target text readers as the source text did on its readers. In his opinion, "the readers of a translated text should be able to comprehend it to the point that they can conceive of how the original readers of the text must have understood and appreciated it", or in a broad sense, "the readers of a translated text should be able to understand and appreciate it in essentially the same manners the original readers slid" (Nida, 2000, p118). It's obvious that Nida is reader-oriented and his theory is for the translator to leave the reader in peace and move the author to the reader.

\section{FOREIGNIZATION}

To enquire into the trend of foreignization in western translation theories, one very important figure must be mentioned, Laurence Venuti and his works The Translator's Invisibility and The Scandals of Translation.

"As a theory and practice of translation, however, a foreignizing method is specific to a certain European countries at particular historical moments" (Venuti, 2004, p20). "A foreignizing strategy in translation was first formulated in German culture during the classical and Romantic periods, perhaps most decisively by the philosopher and theologian Friedrich Schleiermacher" (Baker, 1998, p242). In an 1813 lecture on the different methods of translation, Friedrich Schleiermacher, a German theologian and philosopher, argued, "[...] there are two. Either the translator leaves the author in peace, as much as possible, and moves the reader towards him; or he leaves the reader in peace, as much as possible, and moves the author towards him" (Venuti, 2004, p19-20). Schleiermacher advocated the first method since he thought German "can thrive in all its freshness and completely develop its own power only by means of the most many-sized contacts with what is foreign" (Lefevere, 2004, p165). It suggested that a translator should do his/her best to preserve the strangeness of the source text and expose the target reader to the linguistic and cultural otherness of the source text. Then the translator must adopt "an 'alienating' method of translation, orienting himself/herself by the language and content of the source text. He/she must valorize the foreign and transfer that into the target language" (Monday, 2001, p28).

The two methods were described by Schleiermacher but not liven concrete terms. In 1995, Lawrence Venuti in his work The Translator's Invisibility named the first method "foreignizing method" and the second "domesticating method". According to Venuti, a domesticating method is an ethnocentric reduction of the foreign text to language cultural values, bringing the author back home, and a foreignizing method is an ethno deviant pressure on those values to register the linguistic and cultural difference of the foreign text, sending the reader abroad. From then on, the debate on domestication and foreignization extends from the layer of language involved in the debate on literal translation and free translation to another one of cultural and political connotation.

By his investigation of western translation history and theories, Venuti concludes that fluency has long played a dominant role because the canon of foreign literatures in English is supposed to take shape based on the western ideology (Venuti, 2004). A foreign text, therefore, in the traditional translation practice, is produced in accord with the ethnocentric and imperialist value. Namely, the advocated principle in translation is fluency or domesticating method.

Venuti (2004) believes that a foreignizing translation is highly desirable, as it seeks to resist the dominant target-language cultural values and signify the linguistic and cultural difference of the foreign text instead of eliminating them, which is also the basic idea of the deconstruction translation theory which will be referred to later. It is a strategic cultural intervention pitched against the hegemonic English-language nations and the unequal cultural exchanges in which they engage their global others. From Venuti's point of view, "foreignizing translation in English can be a form of resistance against ethnocentrism and racism, cultural narcissism and imperialism, in the interests of democratic geopolitical relations" (p20). Venuti (2004) advocates and practices a resistant translation strategy, a term synonymous to foreignization, because it locates the alien in a cultural other, pursues cultural diversity, foregrounds 'the linguistic and cultural differences of the source-language text and transforms the hierarchy of cultural values in the target language (p308).

However, he opposes the domesticating translation in the Anglo-American cultures. One reason is that this strategy results in transparent and fluent translations, which in turn lead to the invisibility of translators. Transparency "effaces the work of translation and contributes to the cultural marginality and economic exploitation that English-language translators have long suffered, their status as seldom recognized, poorly paid writers whose work nonetheless remains indispensable because of the global domination of Anglo-American culture" (Venuti,2004, p17). Venuti said that the 
motive of The Translator's Invisibility" is "to make the translator more visible so as to resist and change the conditions under which translation is theorized and practiced today, especially in English-speaking countries" (ibid.), which will later be referred to in another book by Venuti (1998), The Scandals of Translation.

Another reason has much to do with his respect for cultural others and the struggle for cultural equality. For Venuti, translating involves looking for similarities between languages and cultures, only because it means constantly confronting dissimilarities. It can never and should never aim to remove these dissimilarities entirely. A translated text should be the site where a different culture emerges, where the reader gets a glimpse of the cultural other. The prevalence of fluent domestication has supported the developments of British and American cultures that are "aggressively monolingual, unreceptive to the foreign, accustomed to fluent translations that invisibly inscribe foreign texts with English-language values and provide readers with the narcissistic experience of recognizing their own culture in a cultural other" (Venuti, 2004, p15).

The two reasons are: interrelated, because "to recognize the translator's invisibility is at once to critique the current situation and to hope for a future more hospitable to the differences that the translator must negotiate" (Venuti, 2004, p313).

\section{DOMESTICATION AND FOREIGNIZATION IN CHINA}

Translation practice and theory research in China also has a long history. During the development, disputes over domestication and foreinization are intense as well.

According to Wang Dongfeng (2002), the theoretical development of the translation strategies in China can be divided into three phases in chronological order:

1. "Wen" (elegant) versus "Zhi" (simple) in Buddhist Scripture translation;

2. "Literal" versus "Free" in modern times;

3. "Domestication" versus "Foreignization" in contemporary age.

\section{A. First Period}

The debate over "Wen" (文) and "Zhi" (质) began about two thousand years ago in the late Eastern 13an Dynasty. Zhi Qian, a translator of Buddhist scriptures in the Three Kingdom Period, was said to be the first one who recorded the conflict. He complained in the preface to Dhammapada (《法句经序》) that Zhu Jiangyan's translation was almost literal but not elegant. But then He advised "to follow the original without amp modification". Translators of Zhi Qian's time held Buddhist scripture as holy and insisted that Buddha's words should be rendered in a simple way. Therefore, they adhered closely to the original and the "simple" school prevailed. In the Eastern Jin Dynasty, one of the most outstanding translators was Shi Dao'an (AD314-385), who emphasized the principle of "faithfulness" and insisted that translators should "adhere to the original text but not ruin the meaning" (Chen, 2000, p12). The situation that "Zhi" dominated in Buddhist scriptures translation did not change until the time when Kumarajiva (AD344-413), an Indian invited by Shi Dao'an to revise the translation by Chinese Buddhists began to take charge of the translation work in Chang'an. His translations were readable and elegant but sometimes "went too far from the original" (Chen, 2000, p19). According to Liang Qichao, it was Xuan Zang (600-664), one of the greatest Buddihist translator in Tang Dynasty, who balanced "Wen" and "Zhi" so that his translations were a\}\}curate, intelligible and graceful and reached the peak of Buddhist translation in China (Luo, 1984).

\section{B. Second Period}

The first wave of literary translation in China came with Lin Shu's successful rendering of La Dane aux, Camelias in 1899. In order to cater to the taste of the readers, Lin Shu turned to typical Chinese language of that time and domesticated many foreign texts while his credit was more or less compromised by his arbitrary deletion, addition, and rework. Yan Fu, another prominent figure at that time asserted in the preface to his translation of On Evolution in 1898 that "there are three difficult things to do in translating: faithfulness, expressiveness and elegance" (Chen, 2000, p106), which has exerted a tremendous influence upon many succeeding Chinese: translators yet sowed the seeds of a future controversy after May Fourth Movement. The later discussions on "faithfulness" and "expressiveness" gradually evolved into the debate over free translation and literal translation. May Fourth Period was an important time for the development of translation theory in China. The debate over free and literal translation could be regarded as a preliminary form of today's debate on domestication and foreignization.

In the 1920s, to enrich Chinese language by introducing new ways of expressions and retaining the foreign flavor, Lu Xun, one of the most radical representatives of literal translation school, claimed "rather to be faithful in thought than to be fluent in language". He employed many Europeanized structures in his translations as an opposition to fluent translation strategy, a typical example of which is his translation The Collection of Foreign Novels, but this collection only sells less than 60 copies after it was published. Later, his unidiomatic ways of expression which made the target text difficult to be understood were attacked by free translation school. Liang Shiqiu (1902-1987) said that reading Lu's translations was like reading a map and trying to locate places with one's fingers. He noted that they were more than "stiff', and were even "dead translations". In 1930s and 1940s, the free translation school still dominated the field of literary translation field, most literary translators including Fu Donghua paid more attention to the "verve" of original 
texts and the fluency of the translated texts rather than the form of the original texts, what's more, translators even "change the structure of the original text according to their own wishes" (Sun, 2002). But during this debate, especially with the effort of people like Lu Xun, Qian Zhongshu and Guo Moruo, the "faithfulness" school began to take some influence, and many foreign words as well as western grammatical structures were imported which thereby facilitated the development of vernacular Chinese. It is worth noting that $\mathrm{Lu}$ Xun's insistence on literal translation is based on the reform of Chinese language, and it transfers the problems of translation into political problems of literary and cultural reconstruction. Wang Dongfeng that there is a degree of resemblance or even the sameness between Lu Xun's literal translation and Venuti's foreignization(Wang, 2002).

From the late 1930 s on, free translation gradually prevailed in the translation field of China. Recognizing the great linguistic gap between Chinese and western languages, many influential literary translators such as Zhang Guruo, Zhu Shenghao and Fu Donghua had used domesticated language to translate foreign literary works. Their stressed the presentation of the soul of the original text and insisted on natural translation method. Fu Donghua once described Europeanization as "imitation" and said the imitation of foreign things was as deplorable as that of ancient things. He then said that "the beautiful is only what is imagined anal created" (Luo, 1984, p442). In the 1950s, Fu Lei put forward "Resemblance in Spirit" which was borrowed from the theory of Chinese classic painting. In the preface to his revised Chinese version of Balzac's Le Pere Goriot, he said, "in terms of effects, translating is just like painting, both aimed at the resemblance in spirit rather than in form"(Fu, 1984, p20). From then on, literary translation had been uplifted to the realm of aesthetics and arts, and literary translators had set "transference of spirit" as the goal of a successful translation. In 1964, when Qian Zhongshu commented on Lin Shu's translation, he proposed that an ideal criterion of literary translation was "Sublimation" by which he meant:

When translating works, translators are not only supposed to retain the original flavor but also show no unnaturalness caused by linguistic differences between two languages. The target text should be so faithful to the source text that it does not read like a translation because there is not the slightest translation in the source language text.(Luo, 1984, p696)

Fu Lei's "Resemblance in Spirit" and Qian Zhongshu's "Sublimation" had exerted tremendous influence upon later Chinese literary translators and reached the summit of free translation.

\section{C. $\quad$ Third Period}

The debates in the earlier periods were actually of technical level and limited to linguistic problems. Recently, criticism on translation strategies gradually moves out of the scope of language. More and more importance has been attached to cultural research in current translation studies and the ideology behind the process of translating. Many scholars and translation theorists come to realize that they have much in common with the experts in cultural anthropology and there is a need to look beyond the confines of linguistically oriented translation studies and search for cross-cultural approaches. Wang Dongfeng in his essay "About Domestication and Foreignization" says that "the debate on domestication and foreignization can be regarded as the poetic, cultural and political rather linguistic extension of the time-worn controversy over free and literal translation" and asserts "domestication and foreignization can be regarded as the conceptual extension of literal translation and free translation, but they are not the same" (Wang, 2002, p25). Domestication and foreignization, therefore, become the hot topic in the translation circle.

In his essay "Domestication-A Way of Translation", Liu Yingkai argues that "domestication will reconstruct the realities of foreign countries, obliterate the national features, compel them to be assimilated by the target language, and thus distort the original text"(Liu, 1987, p60). He sharply criticizes the prevailing practice of domestication in Chinese translation circle such as the overuse of Chinese four-character phrases, archaisms, images and idioms. Since then, a new round of dispute over domestication and foreignization arises. Guo Jianzhong makes a detailed analysis of the concepts of domestication and foreignization in his essay "A Cultural Approach to Translation" and comes to a conclusion that they will coexist for ever (Guo, 1998). Later, Sun Zhili points out that "foreignization tends to be dominant in China's literary translation in the 21th century"(Sun, 2003, p44). He also provides a further analysis of advisability and feasibility of "Foreignization First, Domestication Second" strategy based on the general trend in current world-wide situation. Cai Ping, however, holds that the purpose of translation is to communicate. Domestication is preferred because it is easy for the readers to understand while foreignization should make it hard for them to read or appreciate. He then draws a conclusion that the latter should give way to the former (Cai, 2002). In the debate over translation strategies, it is apparent that the voice of advocating foreignization sounds louder and many scholars are motivated by Venuti. For them, "the significance of foreignization lies in three aspects: accelerating cultural communication and increasing the target reader's knowledge of the foreign culture; meeting the aesthetic expectations of the target readers for translated literature; benefiting the development of the Chinese language"(Sun, 2003, p49-50).

\section{REFERENCES}

[1] Baker, Mona. (ed.) (1998). Encyclopedia of Translation Studies. London and New York: Routledge.

[2] Dongfeng, Wang. (2002). Domestication and Foreinization: the Confrontation of Spear and Shield? Chinese Translators Journal, 5, 24-26.

[3] Dongfeng, Wang. (2003). An Invisible Hand----Manipulation of Ideology on Translation Practice. Chinese Translators Journal, 5, 16-23. 
[4] Fukang, Chen. (2000). History of Chinese Translation Theories. Shanghai: Shanghai Foreign Language Education Press.

[5] Jianzhong, Guo. (1998). Cultural Factors in Translation: Domestication and Foreinization. Journal of Foreign Languages, 2, 12-18.

[6] Lei, Fu. (1984). Translation Preface of Le Pere Goriot. In the Association of Chinese Translators Collected Papers of Translation Research 1894-1948. Beijing: Foreign Language Teaching and Research Press, 390.

[7] Lefevere, Andrew. (ed.) (2004). Translation / History / Culture. Shanghai: Shanghai Foreign Language Education Press.

[8] Munday, Jeremy. (2001). Introducing Translation Studies: Theories and Applications. London and New York: Routledge.

[9] Nida, Eugene A. (2000). Language, Culture, and Translating. Shanghai: Shanghai Foreign Language Education Press.

[10] Nida, Eugene A. (1964). Toward a Science of Translating. Leiden: E.J.Brill.

[11] Nida, Eugene A. and Charles R. Taber. (1969). The History and Practice of Translation. Leiden: E.J. Brill.

[12] Nida, Eugene A. and Waard, J. (de.) (1986). From One Language to Another: Functional Equivalence in Bible Translation. Nashville: Thomas Nelson.

[13] Ping, Cai. (2002). Domestication Should Be the Dominant Translation Strategy. Chinese Translators Journal, 5, $39-41$.

[14] Robinson, Douglas. (1997). Translation and Empire: Postcolonial Theories Explained. Manchester: St. Jerome.

[15] Shuttleworth, M. and Cowie, M. (2004). Dictionary of Translation Studies. Shanghai: Shanghai Foreign Language Education Press.

[16] Tytler, A. F. (1978). Essay on the Principles of Translation. Ed. J. F. Huntsman. Amsterdam: Benjamins.

[17] Venuti, Lawrence. (2004). The Translator's Invisibility ---- A History of Translation. Shanghai: Shanghai Foreign Language Education Press.

[18] Xinzhang, Luo. (1984). Analects of Translation. Beijing: The Commercial Press.

[19] Yingkai, Liu. (1987). Domestictation----A Forked Road of Translation. Modern Foreign Languages, 2, $60-66$.

[20] Zaixi, Tan. (1991). The Brief History of Western Translation Theories. Beijing: the Commercial Press.

[21] Zhili, Sun. (2003). A Second Essay on Strategies of Literature Translation. Chinese Translators Journal, 1, 48-51.

[22] Zhili, Sun. (2002). Literature Translation in China: From Domestication to Foreinization. Chinese Translators Journal, 1, 40-44.

Lili Wang was born in Qingdao, China in 1978. She received her M.A. degree in linguistics from the Ocean University of China in Qingdao.

She is currently a lecturer in the College of Foreign Languages, Qingdao University of Science and Technology, Qingdao, China. Her research interests include Translation theories and language teaching. 